\title{
A critical comparison of dynamometer data with pin-on-disc data for the same two friction material pairs - A case study
}

\author{
Matteo Federici $^{\mathrm{a}}$, Mattia Alemani ${ }^{\mathrm{b}}$, Cinzia Menapace ${ }^{\mathrm{a}}$, Stefano Gialanella ${ }^{\mathrm{a}}$, Guido Perricone ${ }^{\mathrm{b}}$, \\ Giovanni Straffelini ${ }^{\mathrm{a}, *}$ \\ ${ }^{\text {a }}$ Dept. of Industrial Engineering, University of Trento, Via Sommarive 9, Povo, Trento, Italy \\ ${ }^{\mathrm{b}}$ Brembo S.p.A., Stezzano, Italy
}

\section{A R T I C L E I N F O}

\section{Keywords:}

Pin-on-disc testing

Dynamometer testing

Dry sliding

Brake materials

\begin{abstract}
A B S T R A C T
Friction and wear behavior of brake materials is often investigated using Pin-on-Disc (PoD) or dynamometer tests. Dynamometer tests reproduce the real braking conditions since they are carried out on real parts. whereas PoD tests are carried out using small pins, under constant sliding velocity and contact pressure. In the present technical note, the friction and wear behavior of two commercial friction materials, a low-met and a nonasbestos organic (NAO) material, dry sliding against a pearlitic cast iron counterface disc was investigated. The PoD tests were carried out at room temperature and at $300{ }^{\circ} \mathrm{C}$; the dynamometer tests were conducted simulating urban braking conditions. The experimental data were compared and the main wear mechanisms were identified. The wear mechanisms observed with the PoD at room temperature turned out to be similar to those observed with the dynamometer tests. On the other hand, the $\mathrm{PoD}$ tests carried out at $300{ }^{\circ} \mathrm{C}$ revealed particular features in the friction layer that were not detected in the dynamometric tests. As far as the tribological data are concerned, the average friction coefficients recorded during the dynamometric tests were similar to the values recorded in the PoD tests, whereas the wear coefficients were one order of magnitude lower, most probably due to the limited area of contact of the pins.
\end{abstract}

\section{Introduction}

During braking, the kinetic energy of the vehicle is dissipated and turned into heat by the friction forces between pads and the rotating disc. Commercial discs are typically made of pearlitic cast iron, which exhibits several advantages, including good sliding behavior against different counterface materials, and high thermal conductivity that is helpful for reducing the contact temperature. Friction materials for automotive applications are composites containing even more than 30 ingredients and usually classified as: low-metallic (low-met) and Non Asbestos Organic (NAO) materials. Actually, nowadays, all of them do not contain asbestos. Low-met materials contain a total amount of $\mathrm{Fe}$ and $\mathrm{Cu}$, in the form of powder or fibers, in the range $10-50 \mathrm{wt} \%$ percent, whereas NAO materials contain a lower amount of metallic ingredients, usually below $10 \mathrm{wt} \%$. In addition, low-met materials typically display high values of the friction coefficient (usually in the range 0.4-0.6), whereas NAO materials display lower values of the friction coefficient (around 0.3-0.4) [1,2].

During sliding, friction layers are formed on the contact surfaces. These layers are made of primary and secondary plateaus. Primary plateaus feature hard constituents, such as metallic fibers or ceramic particles, which protrude from the pad surfaces. Secondary plateaus are made of wear debris trapped in between the pad-disc mating surfaces, that pile-up and are compacted against the primary plateaus [4-8]. In general, friction and wear behavior of braking systems are determined by the characteristics and properties of the friction layers that are dynamically formed and disrupted during sliding. Friction and wear tests on brake materials are conducted using full-scale dynamometers or reduced-scale testing rigs. Dynamometer tests are accelerated bench tests, carried out on real parts, reproducing the real braking conditions. On the contrary, small-scale testing rigs, such as the friction assessment screening test (FAST) [9], the Chase machine [10], the reduce-scale dynamometers $[11,12]$ or the Pin on Disc (PoD) tests, are simply used as first screening tests or in the initial stage of the development of new friction materials [11]. In particular, PoD tests, are rather simplified tests since they are typically carried out in drag conditions, i.e., under constant sliding velocity and contact pressure. However, PoD tests feature several advantages, including shorter testing times, lower costs, and the possibility to better relate the friction and wear behavior to the test parameters, such as sliding velocity and contact pressure $[13,14]$.

\footnotetext{
* Corresponding author.

E-mail address: Giovanni.straffelini@unitn.it (G. Straffelini).
} 
Table 1

Concentration of the compounds present in the friction materials (measured by $\mathrm{XRD}$ ). The hardness values are only indicative and were taken from different literature sources.

\begin{tabular}{|c|c|c|c|c|}
\hline Phase (Wt\%) & M1 & M6 & $\begin{array}{l}\text { General purpose of } \\
\text { the compound }\end{array}$ & $\begin{array}{l}\text { Moh's } \\
\text { hardness }\end{array}$ \\
\hline Zinc - Zn & 14.31 & 5.08 & Reinforcement & $2.5-3$ \\
\hline Graphite - C & 39.28 & 31.98 & Lubricant & 1.5 \\
\hline Copper - Cu & 11.16 & 9.00 & Reinforcement & 3 \\
\hline $\begin{array}{l}\text { Silicates - }(\mathrm{K}, \mathrm{Na})(\mathrm{Mg} ; \mathrm{Fe}) \\
\quad\left(\mathrm{AlSi}_{3} \mathrm{O}_{10}\right)(\mathrm{OH})_{2}\end{array}$ & 6.93 & 9.42 & Reinforcement & $5-6$ \\
\hline $\begin{array}{l}\text { Potassium Hexatitanate - } \\
\qquad \mathrm{K}_{2} \mathrm{Ti}_{6} \mathrm{O}_{13}\end{array}$ & 0.75 & 8.37 & Reinforcement & 5 \\
\hline Barite - $\mathrm{BaSO}_{4}$ & 0.00 & 22.88 & Filler & $3-3.5$ \\
\hline Baddeleyite - $\mathrm{ZrO}_{2}$ & 0.00 & 9.85 & Abrasive & 6.5 \\
\hline Fe-alfa - Fe & 3.52 & 0.93 & Reinforcement & $4-4.5$ \\
\hline Moissanite - SiC & 1.80 & 0.00 & Abrasive & $9-9.5$ \\
\hline Chromite - $(\mathrm{Fe}, \mathrm{Mg}) \mathrm{Cr}_{2} \mathrm{O}_{4}$ & 5.61 & 0.00 & Abrasive & 8 \\
\hline Zincite - ZnO & 2.25 & 0.00 & Abrasive & 5.5 \\
\hline Berndtite - SnS 2 & 2.46 & 1.13 & Lubricant & $1-2$ \\
\hline Periclase - MgO & 5.89 & 0.00 & Abrasive & 6 \\
\hline Sphalerite - (Zn,Fe)S & 1.71 & 0.00 & Lubricant & $3.5-4$ \\
\hline Corundum $-\mathrm{Al}_{2} \mathrm{O}_{3}$ & 4.33 & 1.36 & Abrasive & 9 \\
\hline
\end{tabular}

In the present investigation, the dry sliding behavior of two commercial friction materials, a low-met and a NAO, was investigated comparatively, by means of PoD and dynamometric tests, operating in mild conditions in both cases. Friction and wear data were then obtained and the wear mechanisms were analyzed to help in the comparison of the results. The aim of the work was to emphasize some advantages and disadvantages of the two methods in producing useful friction and wear data.

\section{Experimental set-up}

Two commercial friction materials codenamed M1 and M6 were investigated. In Table 1, the identified phases, quantified using an XRay diffraction (XRD) approach are listed [15]. M1 is a low-met material, that contains quite a large amount of abrasives, such as $\mathrm{Al}_{2} \mathrm{O}_{3}$ and chromite; whereas M6 is an NAO material that contains a low amount of abrasives and contains a particularly high concentration of barite. Common feature to both materials is a high concentration of graphite and copper, this latter mainly present in the form of fibers.

Cylindrical pins with a diameter of $6.0 \pm 0.1 \mathrm{~mm}$ and a height of $10.0 \pm 0.1 \mathrm{~mm}$ were machined from the pads and used for the PoD tests. Fig. 1 shows two optical micrographs at low magnification of the test surfaces of both the pin and the pad in case of material M6. The pictures show that the diameter of the pin appears large enough to represent the microstructure of the composite friction material which makes up the brake pad.

The tests were carried out with an average nominal contact pressure of $1 \mathrm{MPa}$ and a sliding velocity of $1.57 \mathrm{~m} / \mathrm{s}$, with a pv-value of $1.57 \mathrm{~m} /$ $\mathrm{s} \mathrm{N} / \mathrm{m}^{2}$ corresponding to mild sliding conditions [16]. The tests were carried out at room temperature $\left(25^{\circ} \mathrm{C}\right)$ and at a disc temperature of $300{ }^{\circ} \mathrm{C}$ to explore the high-temperature behavior of the friction materials, affected by the thermal decomposition of the polymeric binder, i.e., a phenolic resin [1-3]. For the high temperature tests, a close-loop feedback system was used, in which the disc temperature was maintained constant through an infrared high temperature sensor, as described in [17]. The disc was made of pearlitic-bainitic gray cast iron with a hardness of $350 \mathrm{HB}$. Three test repetitions were carried out for each material, and during each test the evolution of the friction coefficient was continuously monitored. The wear of the pin was measured by checking its weight before and after each test, using an analytical balance with a sensitivity of $10^{-4} \mathrm{~g}$. Data were then converted into wear volumes using the measured densities of the friction materials, which were $2.27 \mathrm{~g} / \mathrm{cm}^{3}$ for material M1 and $2.6 \mathrm{~g} / \mathrm{cm}^{3}$ for material M6.
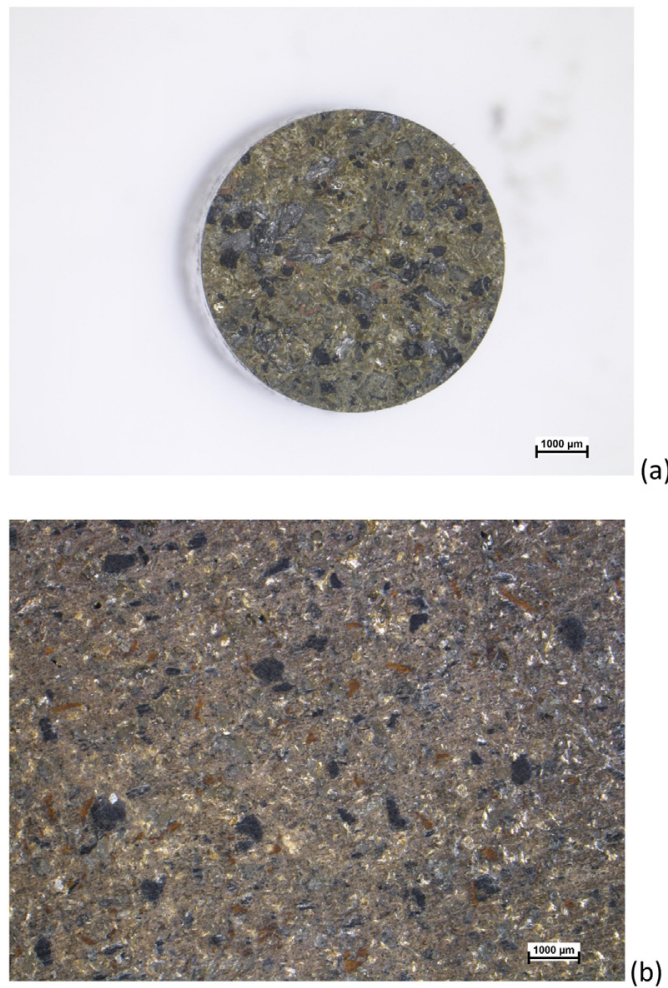

Fig. 1. Optical micrographs of the pin (a) and pad (b) test surfaces of friction material M6.

The disc wear volumes were determined by means of a profilometer. The system specific wear coefficient, $\mathrm{K}_{\mathrm{a}}$, was then calculated using the following relationship:

$K_{a}=\frac{V}{F \cdot S}$

where $\mathrm{V}$ is the system wear volume (pin + disc), $\mathrm{F}$ is the applied load and $\mathrm{s}$ is the sliding distance.

The tests with the inertia brake dynamometer were run following a cycle based on the modified SAE J2707 Method B, shown in Table 2, proposed to simulate mild urban braking conditions [18]. With reference to the original SAE procedure, every brake section was reduced by $10 \%$ in terms of stops number, apart for the burnish section that was kept the same as the original procedure. Moreover, the two highway blocks and the hill descent block were removed [19]. The same type of commercial pads and cast iron discs adopted for producing the PoD pins and discs were used for the dynamometer tests. During each test, the contact pressure and the friction coefficient were continuously monitored. In addition, the evolution of the disc temperature close to the sliding contact was also recorded, using a thermocouple embedded in the disc. Indeed the test was temperature driven, meaning that according to the original SAE procedure the brake action took place only when a defined temperature value was measured on the disc. The system wear was measured by weighting the pads and discs before and after each test, and then calculating the wear volumes, V, using the relevant density values. The system specific wear coefficient, $K_{a}$, was then calculated using the following relationship:

$K_{a}=\frac{\mu \cdot V}{E_{b}}$

where $\mu$ is the average coefficient of friction, and $E_{b}$ is the theoretical braking energy, given by $1 / 2$ I $N \omega^{2}$, where $I$ is the inertia of the main spindle and flywheel, $\omega$ is the initial (i.e., before braking) angular velocity and $\mathrm{N}$ is the total number of brakes. Eq. (2) is a modification of Eq. (1). It was obtained considering that $F=F_{t} / \mu$, where $F_{t}$ is the 
Table 2

Modified SAE J2707 cycle used in the dynomometric tests.

\begin{tabular}{|c|c|c|c|c|c|c|}
\hline & Section & Initial speed $[\mathrm{km} / \mathrm{h}]$ & Final speed $[\mathrm{km} / \mathrm{h}]$ & Initial rotor brake temperature $\left[{ }^{\circ} \mathrm{C}\right]$ & Braking deceleration $[g]$ & Number of stop \\
\hline 1 & Burnish & 50 & 4 & 100 & 0.25 & 100 \\
\hline 2 & Town Block 1 (TB1) & 50 & 4 & 150 & 0.25 & 20 \\
\hline 4 & Country Road Block 1 (CRB1) & 80 & 4 & 200 & 0.35 & 20 \\
\hline 5 & Country Road Block 2 (CRB2) & 100 & 4 & 125 & 0.4 & 20 \\
\hline 7 & Town Block 2 (TB2) & 50 & 4 & 150 & 0.25 & 20 \\
\hline 8 & County Road Block 3 (CRB3) & 100 & 4 & 125 & 0.4 & 20 \\
\hline
\end{tabular}

tangential frictional force, and the product: $F_{t} s$, is the actual braking energy that was theoretically considered equal to $\mathrm{E}_{\mathrm{b}}$. It is expected that Eq. (2) slightly underestimates the wear coefficient. In fact, the actual braking energy is lower than $\mathrm{E}_{\mathrm{b}}$, since $\mathrm{E}_{\mathrm{b}}$ is also affected by the frictional resistance due to cooling air [2].

The characterization of the worn surfaces was conducted in planar and cross sectional modes, using a scanning electron microscope (SEM) equipped with an energy dispersive X-ray spectroscope (EDXS). In the EDXS analyses, carbon and oxygen were not quantified since this technique is not sufficiently reliable for light elements.

\section{Results and discussion}

\subsection{Pin on disc tests}

Fig. 2 shows the evolution of the friction coefficient during the PoD test at room temperature and at $300{ }^{\circ} \mathrm{C}$ in case of material M6. At room temperature, the friction coefficient increases from 0.30 to an average steady-state value of 0.38 . At high temperature, the friction coefficient is seen to decrease from an initial average value of 0.42 to a steady-state value of 0.38 . The M1 materials displays a similar behavior and all the recorded average steady-state values of the coefficient of friction are listed in Table 3. In this table the $\mathrm{K}_{\mathrm{a}}$-coefficients for the pin-disc system are also included. As expected, the low-met M1 material displays higher coefficient of friction and wear rate with respect to the NAO M6 material. At room temperature, wear is definitely mild in both cases, whereas it becomes severe at $300{ }^{\circ} \mathrm{C}$, because of the decomposition of the polymeric binder [17].

As shown in Fig. 3a, the worn out pins of material M1, display the typical friction layer comprising primary and secondary plateaus. In this case, the primary plateaus are made by a Fe fiber (see arrow 1), whereas the gray areas constitute the secondary plateaus (see arrow 2). Similar features are displayed at room temperature and at $300^{\circ} \mathrm{C}$. Since the friction and wear properties of the materials under study are mainly influenced by the characteristics of the secondary plateaus, their elemental composition was measured from EDXS data to obtain additional information. Table 4 contains the average values of such measurements
Table 3

Experimental results of the PoD tests.

\begin{tabular}{cccccc}
\hline \multirow{2}{*}{ Material } & \multicolumn{2}{c}{ Room temperature } & & \multicolumn{2}{c}{$300{ }^{\circ} \mathrm{C}$} \\
\cline { 2 - 3 } \cline { 5 - 6 } \cline { 5 - 6 } & $\mu$ at steady state & $\mathrm{K}_{\mathrm{a}}, \mathrm{mm}^{3} / \mathrm{Nm}$ & & $\mu$ at steady state & $\mathrm{K}_{\mathrm{a}}, \mathrm{mm}^{3} / \mathrm{Nm}$ \\
\hline M1 & 0.55 & $2.8 \cdot 10^{-5}$ & & 0.55 & $3 \cdot 10^{-4}$ \\
M6 & 0.38 & $6 \cdot 10^{-6}$ & & 0.38 & $3 \cdot 10^{-5}$ \\
\hline
\end{tabular}

for material M1. It can be noted that secondary plateaus contain quite a large amount of Fe, confirming that they are mainly made by the compaction of Fe-oxides most of them originating from the wear of the cast iron counterface disc [20,21].

A quite different friction layer was observed on the pin worn surface of material M6, as shown in Fig. 3b. The secondary plateaus are smaller in size, and the whole worn surface appears very flat. This is confirmed by the roughness profiles displayed in Fig. 4, and taken with a stylus profilometer on the worn out surfaces of the pins at the end of the tests at room temperature. The measured $\mathrm{R}_{\mathrm{a}}$-values, representative of the average roughness, were $7.2 \mu \mathrm{m}$ for material M1, and $1.9 \mu \mathrm{m}$ for material M6. Similar observations were obtained for the tests at $300^{\circ} \mathrm{C}$. In Table 5 the results of the EDXS analyses on the secondary plateaus are listed. It can be noticed that the secondary plateaus mainly contain $\mathrm{Ba}$ and $\mathrm{Zr}$ and therefore they are mainly made by the compaction of barite $\left(\mathrm{BaSO}_{4}\right)$ and zirconia $\left(\mathrm{ZrO}_{2}\right)$ wear particles. On the contrary, the $\mathrm{Fe}$ content is relatively low: an indication that the content of Fe oxides is also low. This result can be explained by considering the low content of abrasives in the M6 material. The abrasives are necessary to abrade and remove Fe particles from the cast iron counterfaces, which is the important initial stage for the tribo-oxidative wear and the consequent formation of Fe oxides [22,23]. On the basis of these observations, we can thus explain the particular friction and wear behavior displayed by the two materials. The intense action of the abrasives in M1 induces a relatively high wear rate of the disc and also of the pin, since the secondary plateaus are dynamically formed and disrupted by the local shear stresses due to friction. At the same time, the high content of Fe oxides in the secondary plateaus induces an increase in the contact
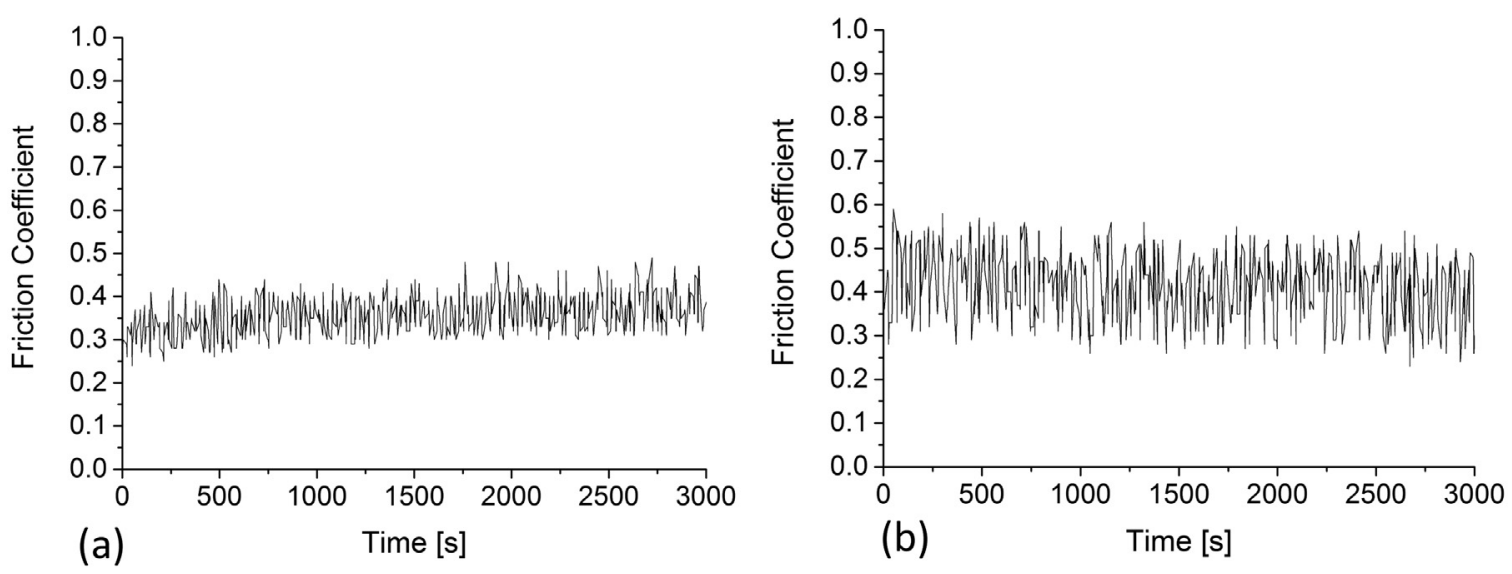

Fig. 2. Evolution of the friction coefficient with time for material M6 tested at room temperature (a) and $300{ }^{\circ} \mathrm{C}$ (b). 


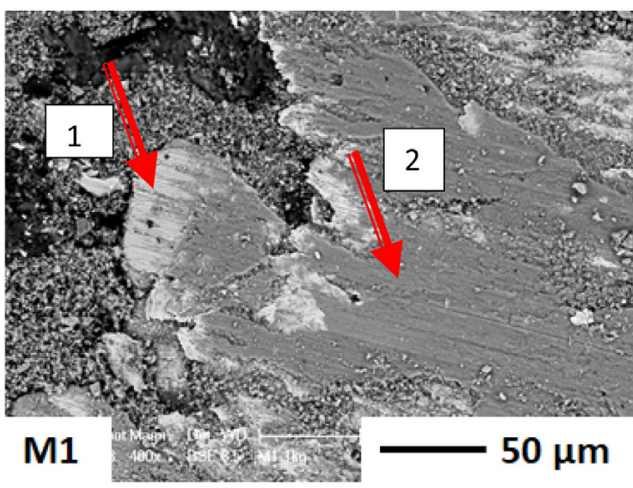

(a)

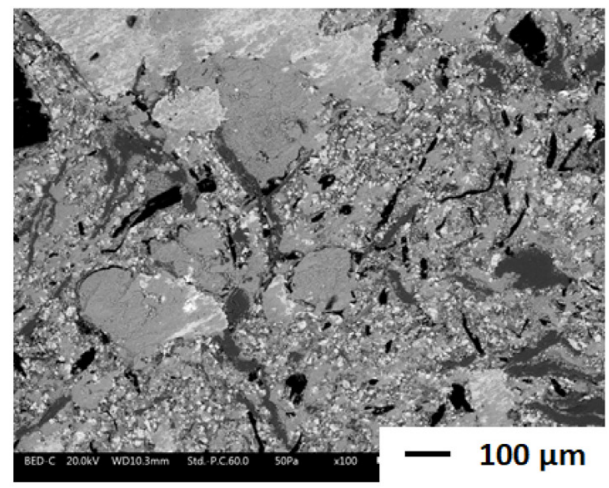

(b)

Fig. 3. SEM micrograph showing the friction layer on the M1 (a) and M6 (b) pins at the end of sliding at room temperature.

Table 4

Elemental compositions of secondary plateaus on the pin surfaces of material M1 as measured from EDXS analysis. Carbon and oxygen are not quantified.

\begin{tabular}{lll}
\hline Element $[w t \%]$ & Room temperature & $300{ }^{\circ} \mathrm{C}$ \\
\hline $\mathrm{Fe}$ & 58 & 49.5 \\
$\mathrm{Cu}$ & 9.50 & 15.2 \\
$\mathrm{Zn}$ & 5.1 & 10.8 \\
$\mathrm{Mg}$ & 15.3 & 7.9 \\
$\mathrm{Al}$ & 4.1 & 2.9 \\
$\mathrm{Si}$ & 4.4 & 4.2 \\
$\mathrm{~S}$ & 2 & 1.5 \\
$\mathrm{Ca}$ & 0.5 & 0.5 \\
$\mathrm{Sn}$ & 1.1 & 7.5 \\
\hline
\end{tabular}

adhesion forces and, thereby, of the friction coefficient. In fact, an increase in Fe oxides in the secondary plateaus induces an increase in the work of adhesion due to the rise in the tribological compatibility of the mating surfaces, considering that the counterface is made of cast iron [13]. In case of material M6, such abrasive interaction is lacking or very much reduced. Therefore, wear is low (both on the disc as well as on the pin since wear is mainly given by the formation and disruption of the friction layers), and consequently the friction coefficient is low because of the low content of Fe oxides on the pin worn surfaces.

The analysis of the cross sections of the M6 worn pins, in correspondence of the friction layers, revealed a particular characteristic. The SEM micrograph in Fig. 5a shows that the friction layer, wherever present, is several hundreds micrometer thick and has a concave morphology. The EDXS maps shown in Fig. 5b-f reveal that it is formed by the intermixing and compaction of different small particles: Fe oxides

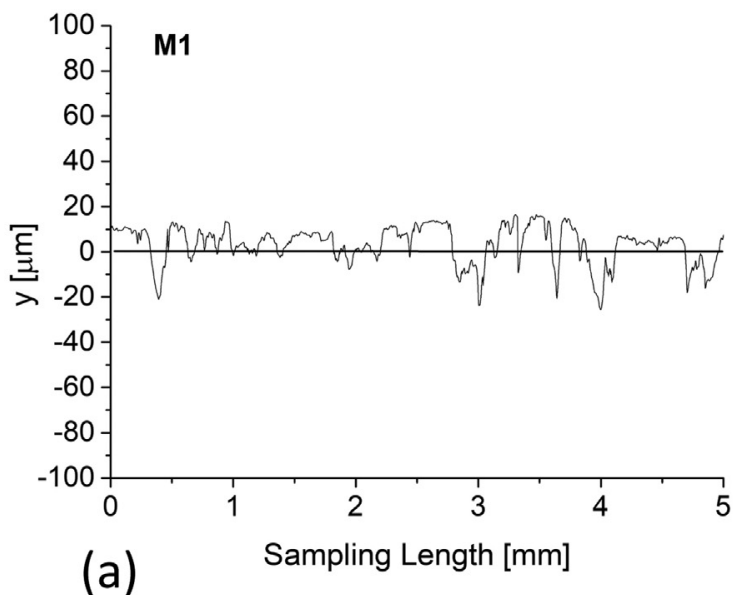

Table 5

Elemental compositions of secondary plateaus on the pin surfaces of material M6 as measured from EDXS analysis. Carbon and oxygen are not quantified.

\begin{tabular}{lll}
\hline Element [wt\%] & Room temperature & $300{ }^{\circ} \mathrm{C}$ \\
\hline $\mathrm{Fe}$ & 7.35 & 4 \\
$\mathrm{Cu}$ & 3.35 & 1.8 \\
$\mathrm{Ba}$ & 24.8 & 27.6 \\
$\mathrm{Zr}$ & 21.7 & 24 \\
$\mathrm{Ti}$ & 17.2 & 14 \\
$\mathrm{~S}$ & 9.43 & 12.6 \\
$\mathrm{~K}$ & 4.45 & 4.1 \\
$\mathrm{Si}$ & 3.87 & 4.5 \\
$\mathrm{Ca}$ & 3.8 & 3.3 \\
$\mathrm{Sn}$ & 1.4 & - \\
$\mathrm{Mg}$ & 1.3 & 2.3 \\
$\mathrm{Al}$ & 0.8 & 2 \\
\end{tabular}

(and possibly, metallic Fe), copper, zirconia and barite. In addition, the friction layer is surrounded by phases rich in carbon, identified as: graphite, phenolic resin and rubber. A scheme for the mechanism of formation of this kind of friction layer is reported in [24]. At the beginning, the situation is as usual: Fe oxide particles (a low amount, though) form and are compacted against a surface obstacle together with other debris from the friction material, such as small barite and zirconia particles. Since the friction layer is formed by very small particles, the local shear action due to friction promotes the onset of turbulent flow which promotes also mechanical mixing. Then, the friction layer becomes thicker for the collapse and thinning of the underlying carbonaceous components. Quite interestingly, the formation of this kind of friction layer was not observed in pins tested at $300{ }^{\circ} \mathrm{C}$. This can

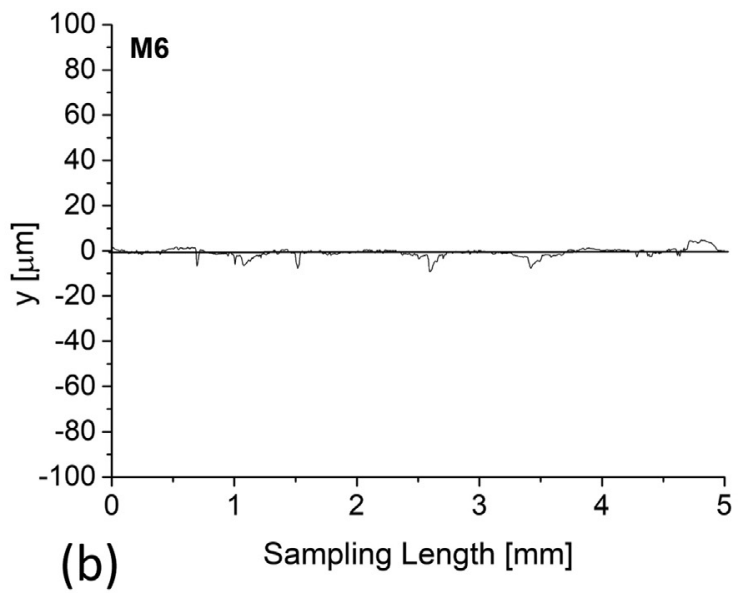

Fig. 4. Roughness profiles taken with a stylus profilometer on the worn of the pins at the end of the tests. (a) material M1; (b) material M6. 


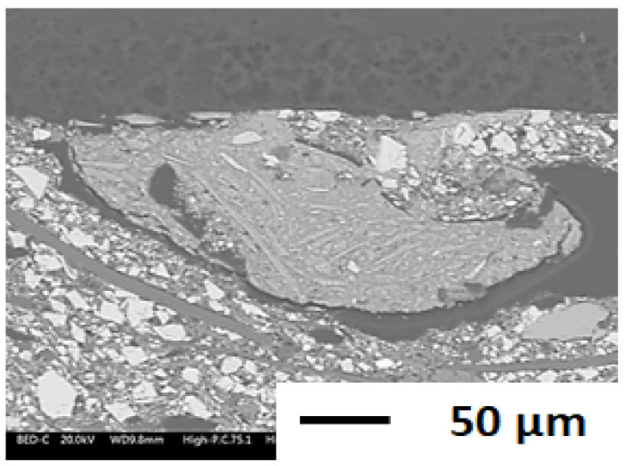

(a)

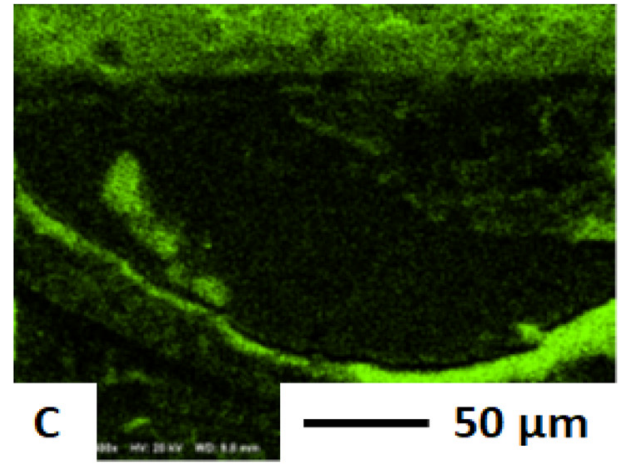

(c)

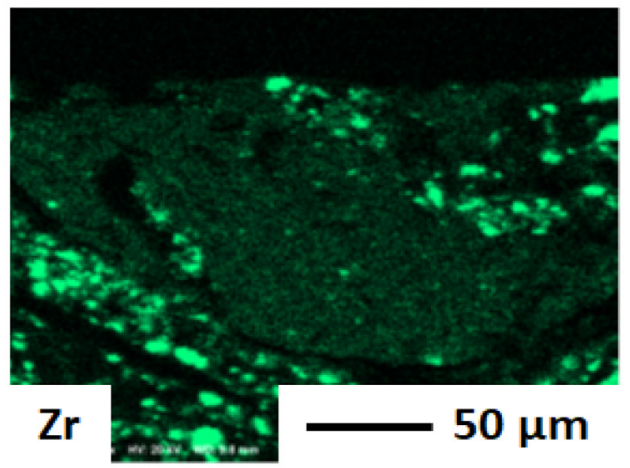

e)

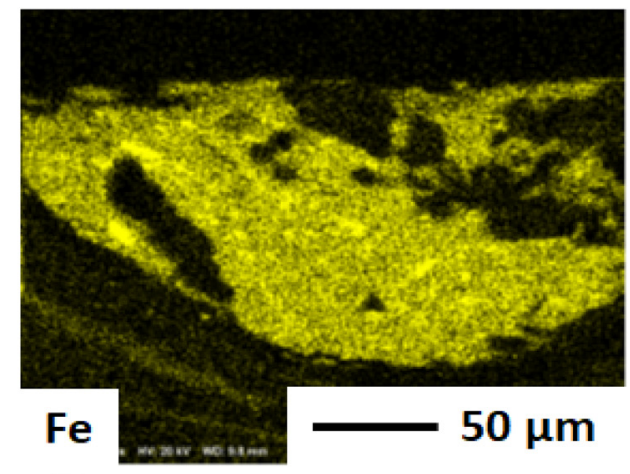

(b)

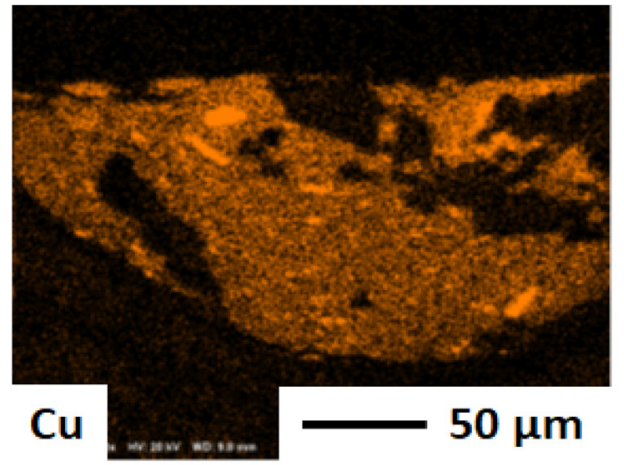

(d)

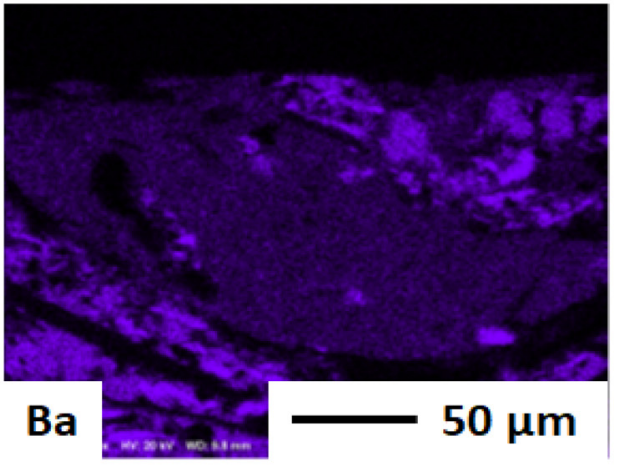

(f)

Fig. 5. (a) SEM image of the thick secondary plateau observed in material M6 (cross sectional view). (b) to (f): EDXS maps of the main recorded elements.

be explained by considering the dramatic increase in the system wear rate (see Table 3 ) due to the degradation of the organic components, above all, of the phenolic binder $[3,17]$. It can be then assumed that at $300^{\circ} \mathrm{C}$ the plateaus are quickly disrupted with the production of wear debris, with no possibility for agglomeration and formation of a thick friction layer.

\subsection{Dynamometric tests}

During each stop of a dynamometric test and between one stop and the subsequent one, the operating parameters, such as: applied pressure, sliding velocity, friction coefficient and contact temperature, all change in an interrelated way. In case of the tests with material M1, the recorded average contact pressure during burnishing was $0.6 \mathrm{MPa}$, and maximum pressure was attained during CRB2 and CRB3 blocks, and was approximately 1.3 MPa. In case of material M6, the recorded contact pressures were higher: the average pressure was $1 \mathrm{MPa}$ during burnishing, and the maximum pressure, attained during CRB2 and
CRB3 blocks, was 1.6 MPa. This result can be explained considering the different frictional performances of the two materials. The measured values of the coefficients of friction are shown by Fig. 6. From these experimental data, the average friction coefficients were calculated, and they turned out to be 0.42 for material M1, and 0.34 for material M6, slightly lower but not much different from the steady-state values obtained in the PoD tests. This means that for material M6 an increased pressure must be applied to obtain the same braking performances at the inertia brake dynamometer.

In Fig. 7, the recorded maximum and minimum values of the disc temperatures are shown. This temperature is proportional to the contact temperature $[2,13]$. It can be firstly observed that the maximum temperature, attained during block CRB1, is always below $300^{\circ} \mathrm{C}$. This supports the view that the dynamometric tests were carried out in mild wear conditions, i.e., below the transition temperature for the friction materials at which the decomposition of the polymeric binder starts. It can be also noted that during each test block, the measured temperatures are lower when using material M1 with respect to material M6. 

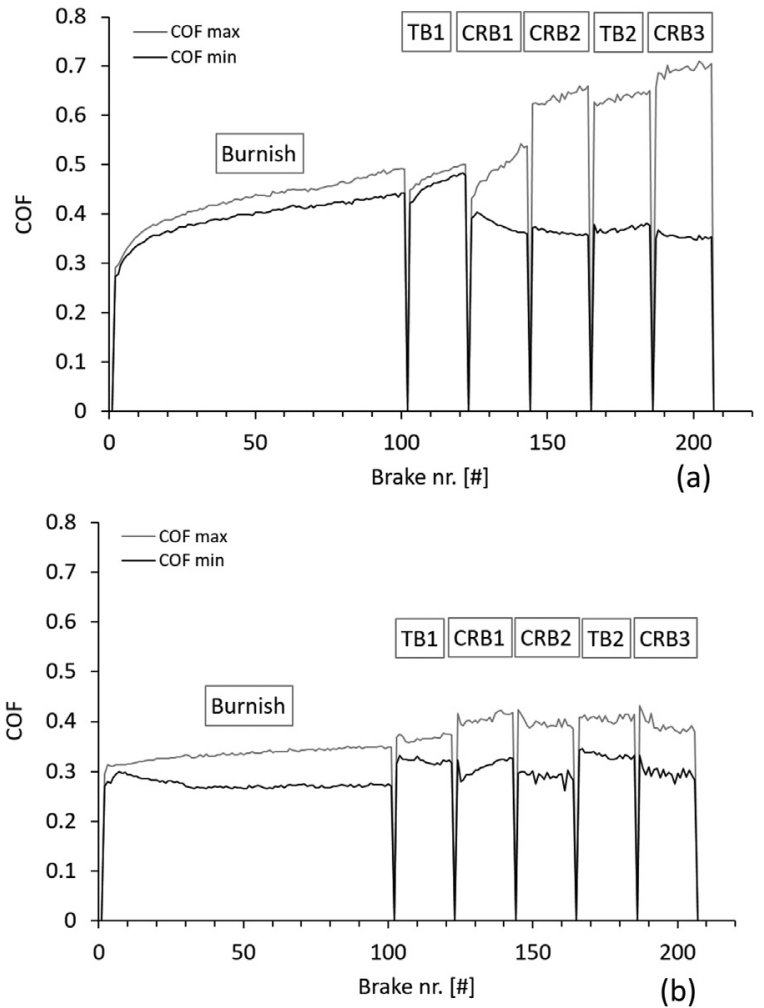

Fig. 6. Minimum and maximum values of the coefficient of friction (COF), as measured from dyno tests, for M1 (a) and M6 (b) friction materials.
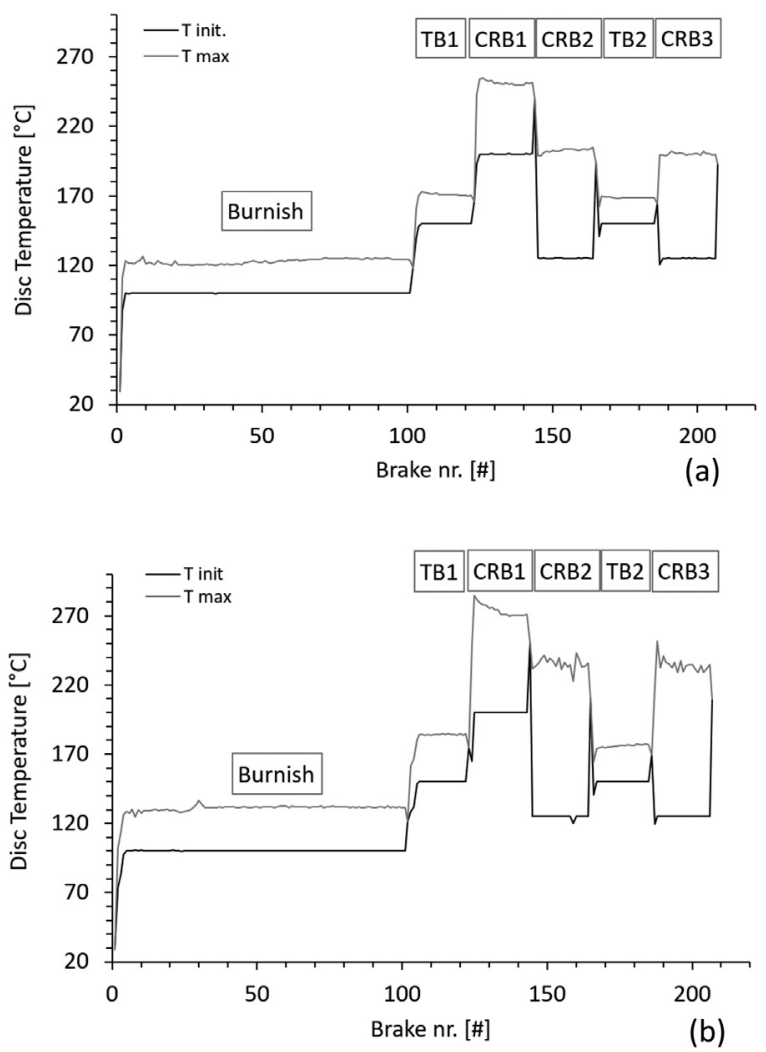

Fig. 7. Initial (minimum) and maximum disc temperature values, as measured from dyno tests, when sliding against M1 (a) and M6 (b) friction materials.
Table 6

Experimental results of the dyno tests.

\begin{tabular}{lllll}
\hline Material & Average COF & Disc mass loss, $g$ & Pad mass loss, $g$ & $\mathrm{~K}_{\mathrm{a}}, \mathrm{mm}^{3} / \mathrm{Nm}$ \\
\hline M1 & 0.42 & 8.2 & 1 & $5.4 \cdot 10^{-6}$ \\
M6 & 0.34 & 6.7 & 4 & $1.4 \cdot 10^{-7}$ \\
\hline
\end{tabular}

Temperature rise is due to frictional heating, and therefore it directly depends on contact pressure, sliding velocity, friction coefficient, and also depends on the thermal properties of the mating materials $[2,25,26]$. From the compositional data in Table 1 , it can be inferred that the thermal conductivity of M1 friction material is most likely higher than that of M6, owing to a significantly higher concentration of metallic components, i.e., copper, zinc and iron, not to mention graphite. The relative better capacity of M1 to dissipate frictional heating towards the cast iron rotor disc would be coherent with the lower temperature reached during dynamometric tests (Fig. 7). Moreover, an overwhelming role can be ascribed to friction coefficient. When using material M6, the friction coefficient is lower but an increased pressure must be applied, as already seen, to get the same braking performances. As a consequence, the product: friction $\times$ pressure, is always higher when using material M6. For example, during burnishing, such a product is approximately $0.24 \mathrm{MPa}$ for M1, and $0.30 \mathrm{MPa}$ for M6.

In Table 6, the average values of the coefficient of friction are listed, together with the results of the wear measurements. The $\mathrm{K}_{\mathrm{a}}$-values are quite low, and for sure typical of mild wear. This is in agreement with the fact that the adopted dynamometric cycle simulates urban conditions, avoiding harsh braking events that could induce a pronounced temperature rise in the contact regions, with consequent possible transition to severe wear. Interestingly, the $\mathrm{K}_{\mathrm{a}}$ value for material M6 is roughly one order of magnitude lower than for material $\mathrm{M} 1$, in agreement with the findings of PoD tests (see Table 3). On the other hand, the $\mathrm{K}_{\mathrm{a}}$-values obtained from the dynamometric tests are approximately one order of magnitude lower than the values obtained with the PoD test. Most probably the reason for this result is related to the limited area of contact of the pins. Therefore, they entail a faster formation-disruption dynamics of the secondary plateaus, which in turn leads to a higher wear rate.

Fig. 8 shows the worn surfaces of the pads at the end of the dyno tests. The morphology of the friction layers is similar to that observed in the PoD tests. In case of material M1, the presence of primary and particularly widespread secondary plateaus. In case of material M6, the worn surface is rather flat and the secondary plateaus appear definitely smaller than in M1.

In Table 7, the results of the EDXS analysis conducted on the secondary plateaus of the two pads confirm the trend observed for the pins (Tables 4, 5). In particular, in case of material M1, the Fe content is really high, confirming that the secondary plateaus are mainly made by Fe oxides. In case of material M6, the Fe content is lower, whereas Ba, $\mathrm{Zr}$ and $\mathrm{Ti}$ are also present, although to a minor extent. The cross sectional observations of the pads reveal similar features as those observed in PoD tested samples, including the peculiar friction layer observed in M6 material, both PoD (Fig. 5) and dynamometer-tested pads (Fig. 9).

\section{Conclusions and final remarks}

In the present technical note, the friction and wear behavior of a semi-met and a NAO friction material dry sliding against a pearlitic cast iron counterface has been investigated through PoD and dynamometric tests carried out in mild wear conditions. The current results and conclusions were based on a limited set of materials under two defined test conditions, and the reported correlations may not apply to other materials and tribosystems. However, considering these limitations, it was found that: 


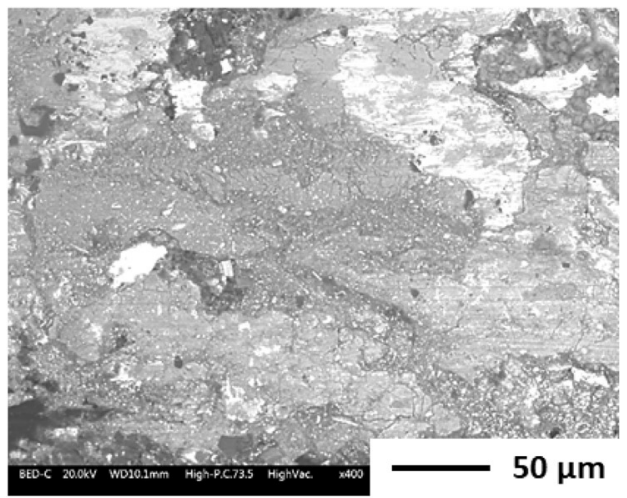

(a)

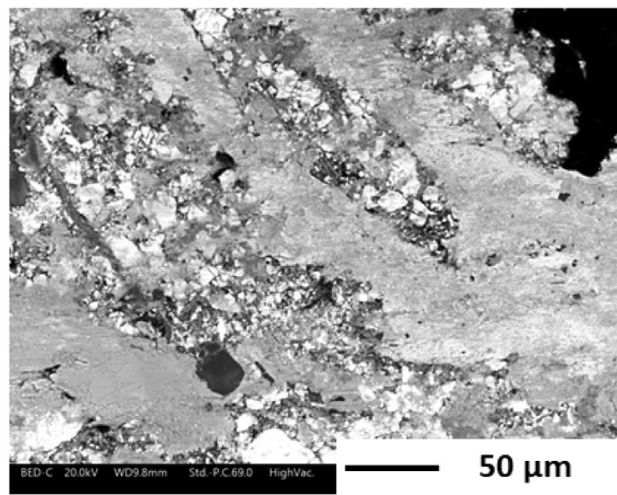

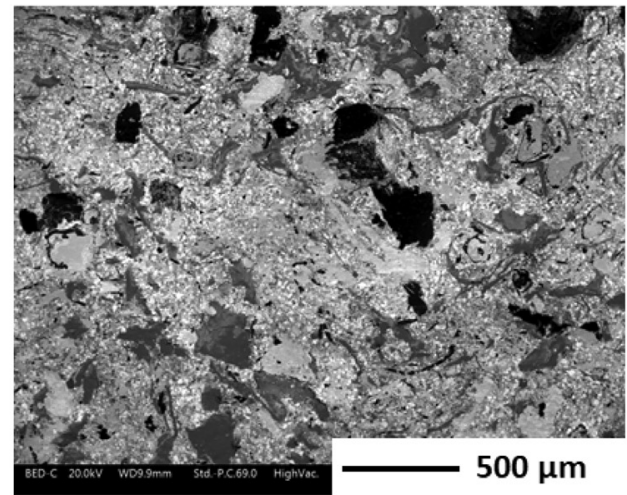

(b)

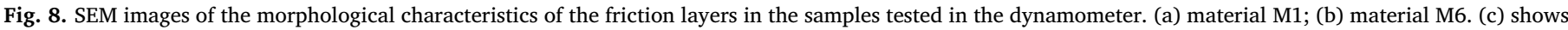
the friction layer of material M6 at a higher magnification.

Table 7

Elemental compositions of secondary plateaus on the pad surfaces of materials M1 and M6 (dynamometer tests) as measured from EDXS analysis. Carbon and oxygen are not quantified.

\begin{tabular}{lll}
\hline Element [wt\%] & M1 & M6 \\
\hline $\mathrm{Fe}$ & 76.5 & 17.5 \\
$\mathrm{Cu}$ & 7.7 & 10.0 \\
$\mathrm{Ba}$ & & 25.5 \\
$\mathrm{Zr}$ & & 18.0 \\
$\mathrm{Ti}$ & & 10.9 \\
$\mathrm{~S}$ & 1.5 & 8.0 \\
$\mathrm{Cr}$ & 0.6 & \\
$\mathrm{Si}$ & 1.9 & 3.7 \\
$\mathrm{Ca}$ & 1.4 & 3.2 \\
$\mathrm{Sn}$ & 1.2 & \\
$\mathrm{Mg}$ & 1.2 & 0.5 \\
$\mathrm{Al}$ & 1.8 & 0.3 \\
$\mathrm{Zn}$ & 4.4 & \\
$\mathrm{~K}$ & & 2.7 \\
\hline
\end{tabular}

1) The PoD tests at room temperature show that wear was mild for both materials. The steady-state friction coefficient and the system specific wear coefficient for the NAO material are lower than for the low-met material. This behavior was explained considering the characteristics of the friction layers, and in particular their content of Fe-oxides. The friction layer of material M6 is quite thick and displays a particular vortex-like morphology, depending on turbulent motions of the finer fraction of the wear debris.

2) The PoD tests at $300{ }^{\circ} \mathrm{C}$ show that wear was severe for both materials. For material M6, the particular morphology of the friction layer detected at room temperature was not observed.

3) The applied average contact pressure during the dyno tests was higher when using material M6 than material M1, and this was attributed to its lower friction coefficient, in agreement with the PoD

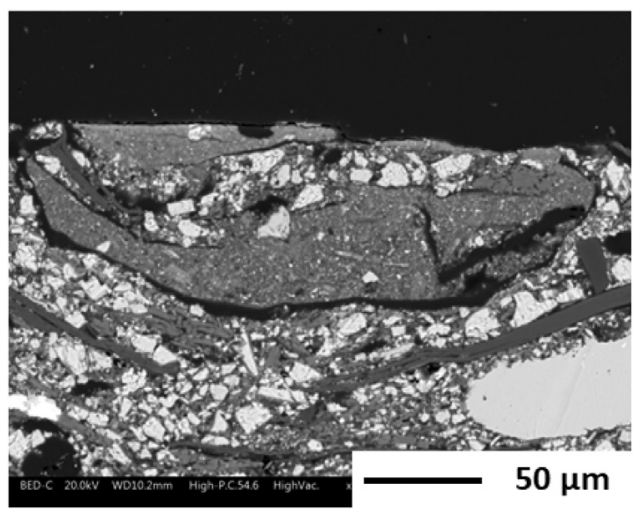

Fig. 9. SEM micrograph showing the thick friction layer forming on the pad made by friction material M6 (cross sectional view).

tests.

4) The system $K_{a}$-values obtained from the dynamometer tests are proportional to the corresponding values obtained with the PoD at room temperature. This is in agreement with the similarity in the friction layers observed at the end of the PoD tests at room temperature and dynamometer tests. In case of material M6, the particular thick layers with concave morphology were also observed.

5) However, the system $\mathrm{K}_{\mathrm{a}}$-values obtained from the dynamometer tests are one order of magnitude lower than the corresponding values obtained with the PoD at room temperature, and this was explained considering the limited extent of the pin contact area that accelerated the formation/disruption processes of the secondary plateaus.

6) Additional tests and a specific modelling are required to better elucidate the limits of using reduced-scale testing in characterizing 
the tribological behavior of brake materials.

\section{Acknowledgments}

The research has received financial support by the EIT-Raw Materials through the EU Project: ECOPADS - Eliminating Copper from brake PADS \& recycling. - n. 17182.

\section{References}

[1] A.E. Anderson, Friction and wear of automotive brakes, ASM Handbook, 1992, pp. 569-577.

[2] A.J. Day, Braking of Road Vehicles, Elsevier, 2014.

[3] R.C. Dante, Handbook of Friction Materials and their Applications, Woodhead Publishing, 2015.

[4] M. Eriksson, F. Bergman, F. Jacobson, On the nature of tribological contact in automotive brakes, Wear 252 (2002) 26-36.

[5] M. Eriksson, F. Jacobson, Tribological surfaces of organic brake pads, Tribol. Int. 33 (2000) 817-827.

[6] W. Österle, I. Urban, Third body formation on brake pads and rotors, Tribol. Int. 39 (2006) 401-408.

[7] P.C. Verma, L. Menapace, A. Bonfanti, R. Ciudin, S. Gialanella, G. Straffelini, Braking pad-disc system: wear mechanisms and formation of wear fragments, Wear 322-323 (2015) 251-258.

[8] G. Straffelini, P.C. Verma, I. Metinoz, R. Ciudin, G. Perricone, S. Gialanella, Wear behavior of a low metallic friction material dry sliding against a cast iron disc: role of the heat-treatment of the disc, Wear 348-349 (2016) 10-16.

[9] A.E. Anderson, S. Gratch, H. Hayes, A new laboratory friction and wear tester for the characterization of brake linings, Society of Automotive Engineers Paper, 1967, p. 670079.

[10] A.J. Burkman, F.H. Highly, Laboratory evaluation of brake lining materials, Society of Automotive Engineers Paper, 1967, p. 670510.

[11] P.G. Sanders, T.M. Dalka, R.H. Bash, A reduced-scale brale dynamometer for friction characterization, Tribol. Int. 34 (2001) 609-615.

[12] N. Perzborn, C. Agudelo, G.P. Ostermeyer, On similarities and differences of measurements on inertia dynamometer and scale testing tribometer for friction coefficient evaluation, SAE Int. J. Mater. Manuf. 8 (2015) 104-117.

[13] G. Straffelini, Friction and Wear, Methodologies for Design and Control, Springer International Publishing, Switzerland, 2015.

[14] J. Wahlstrom, A. Södeberg, L. Olander, A. Jansson, U. Olofsson, A pin-on-disc simulation of airborne wear particles from disc brakes, Wear 268 (2010) 763-769.

[15] L. Lutterotti, Total pattern fitting for the combined size-strain-stress-texture determination in thin film diffraction, Nucl. Instrum. Methods Phys. Res.: B Beam Interact. Mater. At. 268 (3) (2010) 334-340.

[16] G. Straffelini, L. Maines, The relationship between wear of semimetallic friction materials and pearlitic cast iron in dry sliding, Wear 307 (2013) 75-80.

[17] P.C. Verma, R. Ciudin, A. Bonfanti, P. Aswath, G. Straffelini, S. Gialanella, Role of the friction layer in the high-temperature pin-on-disc study of a brake material, Wear 346-347 (2016) 56-65.

[18] SAEJ2707, Wear Test Procedure on Inertia Dynamometer for Brake Friction Materials, SAE International, 2005.

[19] G. Perricone, J. Wahlstrom, Towards the ranking of airborne particle emissions from car brakes - a system approach, in: Proceedings IMechE Part D: J. Automobile Engineering, pp. 1-17.

[20] A. Wirth, D. Eggleston, R. Whitaker, A fundamental tribochemical study of the third body layer formed during automotive friction braking, Wear 179 (1994) 75-81.

[21] R. Hinrichs, M.A.Z. Vasconcellos, W. Österle, C. Prietzel, A TEM snapshot of magnetite formation in brakes: the role of the disc's cast iron graphite lamellae in third body formation, Wear 270 (2011) 365-370.

[22] M. Federici, S. Gialanella, M. Leonardi, G. Perricone, G. Straffelini, A preliminary investigation on the use of the pin-on-disc test to simulate off-brake friction and wear characteristics of friction materials, Wear 410-411 (2018) 202-209.

[23] M.H. Cho, S.J. Kim, D. Kim, H. Jang, Effects of ingredients on tribological characteristics of a brake lining: an experimental case study, Wear 258 (2005) 1682-1687.

[24] C. Menapace, M. Leonardi, V. Matejka, S. Gialanella, G. Straffelini, Wear 398-399 (2018) 191-200.

[25] D. Majcherczak, P. Dufrénoy, M. Naït-Abdelaziz, Third body influence on thermal friction contact problems: application to braking, J. Tribol. 127 (2005) 89-95.

[26] G. Straffelini, S. Verlinski, P.C. Verma, Wear and contact temperature evolution in pin-on-disc tribotesting of low-metallic friction material sliding against pearlitic cast iron, Tribol. Lett. 62 (2016) 36. 